\title{
TITULOS DE CRÉDITO: ORIENTAÇÕES SOBRE O CHEQUE
}

\author{
Wesley Aparecido da Silva ${ }^{1}$, Camila Cortes do Carmo ${ }^{2}$, Pedro Teófilo de Sá ${ }^{1}$ \\ Universidade do Oeste Paulista - UNOESTE. ${ }^{1}$ Curso de Direito, Presidente Prudente - SP. ${ }^{2}$ Curso de Ciências Contábeis, \\ Presidente Prudente - SP. E-mail: wesley as.95@hotmail.com
}

\section{RESUMO}

O objetivo geral da pesquisa é estudar o cheque sem suficiente provisão de fundos, e o objetivo específico consiste em analisar as consequências da sua emissão e recebimento pelas partes, credor e devedor. Os títulos de crédito são documentos utilizados para comprovação de um valor literal e autônomo devido. Existem vários tipos de títulos de crédito que podem ser utilizados por pessoas jurídicas ou físicas, a exemplo do cheque que é objeto deste estudo. O cheque, por ser ordem de pagamento à vista também poderá circular pré-datado, figurando como promessa de pagamento. Nesse caso, as partes firmam nova relação jurídica obrigacional verbal, devendo ser respeitada a nova data para pagamento. $O$ desrespeito à nova relação jurídica firmada poderá gerar direito a indenização ao emitente, quando houver prejuízo financeiro.

Palavras chave: Títulos de Crédito; Cheque; Promessa de pagamento; Insuficiência de fundos.

\section{TITLES CREDIT: GUIDANCE ON CHEQUE}

\begin{abstract}
The general issue of the research is to study the check without sufficient provision of funds, and the specific issue is to analyze the consequences of the emission and receipt by the parties, creditor and debitor. The titles are documents used to evidence of an autonomous literal value due. There are many kinds of titles that can be used by judge person (company) or personal, for as the check that is the subject of this study. The check is on order pay instantly can also pre-dated circular, appearing as a promise to pay. In this case, the parties firm new verbal obligatory legal relationship and must be respected the new date for payment. The disrespect the new verbal obligatory legal relationship may generate some right reparation to the emitter when will be a financial damage.
\end{abstract}

Keywords: Titles of credt; Check; Promise of payment; Insufficient funds. 


\section{INTRODUÇÃO E JUSTIFICATIVA}

O direito de crédito da pessoa, na antiguidade, acabou vinculando a pessoa e o patrimônio, época em que o devedor poderia responder pela dívida com o próprio corpo, sua liberdade, com a vida e até mesmo com a vida dos seus.

Posteriormente, na Idade Media passou a vigorar a separação do patrimônio e da pessoa. A partir de então, o patrimônio do devedor passou a ser utilizado como forma de garantia, porém, havia a dificuldade no transporte dos bens dados em garantia.

Percebendo a necessidade da circulação deste patrimônio com segurança, passou a ser utilizado o papel, denominado cártula, para representação do valor do patrimônio. A cártula servia para as negociações, entretanto com essa mudança, surgiu o problema da garantia, pois o devedor apresentava a cártula para o credor (comerciante), mas esta cártula não possuía bens representativos para liquidar a divida.

Os títulos de crédito cumprem satisfatoriamente a sua função de circulação de riquezas desde a antiguidade até os dias de hoje, tempo em que entram em período de decadência, que poderá levar até mesmo ao seu fim como instituto jurídico. (COELHO, 2013 p. 458-459).

Dentre os vários tipos de títulos de crédito, o presente trabalho abordará apenas aqueles mais conhecidos e o mais utilizado, no meio comercial, o cheque, como forma de pagamento ainda existente.

O objetivo geral do da pesquisa é estudar o cheque sem suficiente provisão de fundos, tendo como objetivo específico analisar as consequências da sua emissão e recebimento para as partes, credor e devedor. Embora a utilização do cheque esteja caindo em desuso, ainda é uma prática corrente, por isso, faz-se necessário esclarecer acerca das consequências da utilização e recebimento deste título.

\section{METODOLOGIA}

A presente pesquisa utilizou o tipo de abordagem qualitativa, visto que o tema abrange aspectos teóricos sobre os títulos de crédito. E como instrumento de coleta de dados utilizou-se a pesquisa bibliográfica, visando à busca por diferentes abordagens sobre os tipos de títulos de crédito, sendo utilizados para isso livros, artigos científicos e revistas eletrônicas.

\section{RESULTADOS}

A desvinculação do direito de crédito da pessoa teve uma grande contribuição na Idade Média, quando o patrimônio do devedor passou a responder pela obrigação, que era 
representada pelo título de crédito. Porém, um problema persistia, a questão da garantia. Mesmo assim, o mencionado título atendeu à função de circular as riquezas, em que pese na atualidade estar sendo pouco utilizado.

Dentre as várias espécies de títulos representativos do direito de crédito, merece destaque apenas o cheque, que constitui objeto deste trabalho. Nessa linha o respeito aos princípios norteadores dos títulos de crédito continuam valendo, até porque o cheque não deixou de ser uma ordem de pagamento à vista.

O estudo acerca do cheque desperta duas preocupações, uma quando é emitido sem suficiente provisão de fundos, e outra quando pré-datado, pois se trata de ordem de pagamento à vista. No primeiro caso, o credor deverá estar atento para as providências a serem tomadas, dentre elas o prazo para execução e a implicação penal. Já no segundo caso, trata-se de promessa de pagamento, uma obrigação pactuada entre as partes que tem o condão de vincula-las à nova avença que deverá ser respeitada. Ademais, o cheque passará a ser uma simples promessa de pagamento, equiparando-se à Nota Promissória.

Uma vez emitido o cheque pós-datado, cria-se um negócio jurídico que não poderá ser desrespeitado pelo credor. Caso ocorra o descumprimento da nova obrigação firmada poderá gerar o dever de responsabilidade e indenização por danos materiais e morais, eventualmente existentes.

\section{DISCUSSÃO}

Os títulos de crédito são documentos utilizados para recebimento de crédito, e provam a existência da divida, permitindo a cobrança. Portanto, representa papel, cártula, e devem respeitar os princípios da cartularidade, literalidade e autonomia para que tenham validade jurídica, já que contém o valor de uma divida a qual deverá ser paga por um credor.

Conforme Coelho (2013 p. 443-444) “O título prova a existência de uma relação jurídica especificamente, duma relação de crédito; ele constitui a prova de que certa pessoa é credora de outra; ou de que duas ou mais pessoas são credoras de outras".

O primeiro princípio a ser tratado será o da cartularidade, pois para que seja um de instrumento de credito exige-se que o credor porte a cártula em original para que possibilite a circulação do credito; é a existência do documento e a sua exibição que possibilita o exercício do direito creditório nele expresso. 
Conforme Negrão (2012 p. 40) “A pessoa detentora do titulo - de boa fé - é reconhecida como credora da prestação nele incorporada e, inversamente, sem a apresentação do titulo não há como obrigar o devedor a cumprir a obrigação inscrita no titulo".

O segundo princípio que garante a validade do título é a literalidade que expressa a garantia de que o que será devido será o valor que estiver grafado por extenso e não a representatividade numérica. (NEGRÃO 2012 p. 43)

O último princípio, não menos importante, é o da autonomia, que representa a validade da obrigação, independentemente da sua vinculação com quaisquer outros documentos, possibilitando a circulação. Segundo Gonçalves (2011, p. 13) “o que efetivamente circula é o título e não o direito abstrato que nele se contém, ou seja, o possuidor exerce direito próprio que não se vincula às relações entre os possuidores anteriores e o devedor". Isto é, cada relação é autônoma em relação às suas antecessoras.

Com exceção da duplicata que é um título de crédito casual, necessita de uma causa, um documento para validação do mesma, a emissão da nota fiscal fatura, os demais títulos de crédito circulam autônomas, independentes.

Dentre as várias espécies de títulos, os mais utilizados são a duplicada, nota promissória e o cheque.

De acordo com Gonçalves (2011, p. 92) “A duplicata é um título sacado exclusivamente em razão de venda a prazo de mercadorias ou de prestação de determinado serviço para cobrança futura". É, portanto, um título que resulta do negócio jurídico denominado compra e venda mercantil ou de uma prestação de serviços e tem por finalidade documentar o credito originário de um destes contratos e devem se pautar na causalidade, representada pela nota fiscal.

A nota promissória é uma promessa de pagamento, emitida pelo próprio devedor, que assume a responsabilidade da quitação do valor especificado no documento, em data futura. Segundo Coelho (2013, p. 504) “a nota promissória é uma promessa de pagamento, seu saque gera, em decorrência, de duas situações jurídicas distintas: a de quem, ao praticar o saque, promete pagar; e a do beneficiário da promessa".

O cheque é um dos títulos de crédito mais conhecidos e mais utilizados, é uma ordem de pagamento a vista, onde o emitente cria uma relação jurídica com o sacado, ou terceiros, com a previsão de que haverá saldo para liquidação da divida. Conforme Negrão (2012, p. 115):

Cheque é ordem de pagamento a vista, emitida por pessoa física ou jurídica, em favor próprio ou de terceiro, contra instituição bancária ou financeira que the seja equiparado, com a qual emitente mantém contrato que autorize a dispor de fundos existentes em conta corrente. 
Em que pese o cheque representar uma ordem de pagamento à vista, é comum a sua emissão e circulação, na forma pré-datada. Nesse caso, ele perde a característica de ordem de pagamento à vista para se tornar uma promessa de pagamento, equiparando-se a nota promissória.

Uma vez emitido o título, este poderá circular no mercado por meio do endosso em branco ou em preto, que são formas de transferência de titulo de crédito, representada pela tradição da cártula, podendo o credor exigir o aval, uma modalidade de garantia. (GONÇALVES, 2011 p. 44). No endosso em preto indica-se o seu beneficiário, o endossatário; já no endosso em branco, não se indica o endossatário, transformando-se em título ao portador.

Nota-se que aval e endosso se diferem, este é a transferência do título, já aquele é somente garantia de pagamento por isso "o aval é o ato cambiário pelo qual uma pessoa (avalista) se compromete a pagar o titulo de crédito, nas mesmas condições que um devedor deste título (avalizado)". (COELHO, 2013 p. 484)

Após emissão do cheque com endosso ou avalizado, o credor recebe esta cártula como pagamento de uma divida, corre o risco de não haver saldo na conta do seu emitente para liquidar o valor do título, caracterizando assim um cheque sem fundos, conforme determina o art. 4 da Lei no 7.357/85.

"Verificado o banco sacado, no procedimento de liquidação do cheque, não possuir o emitente fundos suficientes em sua conta de depósito, deve restituir o título a quem lho apresentara, com a declaração correspondente". (COELHO, 2013, p. 521).

Ao ser devolvido o titulo para o credor alguns caminhos poderão ser tomados, dentre eles o protesto e ou a ação de execução, além de consequência na área penal.

Protesto é o ato o qual se prova que o emitente não cumpriu a obrigação com o credor, podendo este encaminhar o titulo ao cartório de protestos a fim de que fique provada a falta de cumprimento do pagamento por parte do emitente. Segundo art. 1ㅇ da Lei no 9.492/97 "é o ato formal e solene pelo qual se prova a inadimplência e o descumprimento de obrigação originada em títulos e outros documentos de dívida".

De acordo com Coelho (2013 p. 521-522), o cheque sem fundos deverá ser protestado durante o prazo de apresentação, assim em se tratando de título emitido na mesma praça de pagamento, o credor deve encaminhá-lo ao cartório de protesto, nos 30 dias seguintes ao saque; se de praças diferentes, o prazo será de 60 dias.

Levado o título a protesto, deve o credor em quatro dias comunicar o endossante e seu emitente. 
Segundo Almeida (2006, p. 387-390) em se tratando de emitente e seu avalista o ato de protesto e a ação executória são facultativos. Já no caso de coobrigados, endossantes, e avalistas decorrentes das transferências as ações tornam-se obrigatórias, é necessário a prova do não pagamento pelo protesto para requerer ação de execução, a fim de receber efetivamente o valor do título.

O emitente e devedor, nesta situação, é certo que sofrerá sérias consequências, advindas da emissão e devolução de cheques sem a devida provisão de fundos, pois com o protesto, como afirma Cerveira Filho (2004), há o envio do nome e identificação, CPF, do emitente, aos órgãos de proteção ao crédito, e este fica negativado, perdendo seu crédito na praça.

A consequência é que o nome é inscrito no cadastrado de emitente de cheques se fundos, CCF, o que provoca além da restrição de crédito, também a restrição de emissão de novos talões com o banco. (SIQUEIRA, 2005)

Quando o emitente liquidar a divida, poderá ser requerido cancelamento do registro do protesto, como prevê o art. 26 da Lei no 9.492/97, "o cancelamento do registro do protesto será solicitado diretamente no Tabelionato de Protesto de Títulos, por qualquer interessado, mediante apresentação do documento protestado, cuja cópia ficará arquivada".

Outra opção disponibilizada ao credor, portador da cártula, é o manejo da ação executória contra o devedor e até mesmo contra os coobrigados (endossantes e avalistas).

Ação de execução é o procedimento pelo qual o credor do cheque sem fundos vai a juízo pretendendo o recebimento. Observando rigorosamente o prazo de 30 ou 60 dias, para apresentação do título a pagamento, o credor possui6 meses para executar o cheque; passado tal prazo, não há possibilidade de se promover a ação de execução.

Promovida a execução do título, o emitente possui três dias para efetivamente, pagar sua divida, sob pena de penhora de seus bens móveis, imóveis e semoventes, bem como dinheiro, pedras preciosas, móveis, veículos, dentre outros. (ALMEIDA, 2006 p. 439). Neste prazo de três dias, se o emitente não efetuar o pagamento, um oficial de justiça aplicará a penhora dos bens, conforme disposto no art. 652, § 1으, do Código de Processo Civil.

Decorrido o prazo da ação de execução, ao portador do titulo cabe a ação monitoria, que possui prazo prescricional de 5 anos a contar do dia seguinte à data de emissão estampada na cártula. Assim, o credor deve se preocupar com os prazos prescricionais, para a execução e para a ação monitória.

Com a emissão do cheque sem insuficiência de fundos há consequências no âmbito penal. Nesse sentido, afirma Capez (2011, p 574) “É o dolo, consubstanciado na vontade livre e 
consciente de realizar a conduta fraudulenta em prejuízo alheio". Portanto, é necessário um fim especial de agir, consciente na vontade de obter vantagem ilícita para si ou para outrem.

Se o emitente agir com má-fé sabendo que não haverá fundo para liquidação do valor do titulo, induzirão credor a erro, fazendo-o crer que na data da apresentação do título haverá o pagamento. Em virtude da ação do emitente em fraudar o pagamento poderá gerar uma reação do credor, que poderá pedir a instauração do boletim de ocorrência por ter havido o delito de estelionato. Comprovado o fato aplica-se ao emitente a reclusão de 1 (um) a 5 (cinco) anos e/ou multa indenizatória.

Cabe observar que quando se tratar de cheque pós-datado, as normas penais não se aplicam no caso, já que ao ser pré-datado, perde a característica de ordem de pagamento à vista e passa a figurar como promessa de pagamento (ANDREATTA, 2004, p. 43), com isto não é mais apreciado pelo direito penal, sendo possível somente a procedência com protesto e/ou ação de execução.

Caso o credor tenha aceitado e acordado sobre a pré-data, não poderá descumprir a avença, sob a pena de ser responsabilizado pelos danos que causar ao emitente, visto que houve um acordo, caracterizado como contrato verbal, e este ao descumpri-lo está violando o direito de pagamento.

Conforme Andreatta (2004, p. 71), o fato de ter sido depositado antecipadamente o cheque, ferindo o acordo verbal, poderá gerar além da responsabilidade pelos danos materiais, mas também pelos morais.

\section{CONSIDERAÇÕES FINAIS}

Após os estudos sobre títulos de crédito, objetivando-se em estudar os cheques sem provisão de fundos e demonstrar as consequências da sua emissão, foi possível verificar que a utilização do cheque é simples e prática e, em que pese ser uma ordem de pagamento à vista, é comum as pessoas utilizarem na forma pré-datado. Neste caso, as partes firmam um acordo verbal programando a data do pagamento do cheque, ocasião em que ele se reveste da característica da nota promissória, haja vista se tratar de promessa de pagamento.

No caso da emissão de cheque sem suficiente provisão de fundos, caberá ao portador do título o apontamento a protesto, a execução e até mesmo a elaboração de boletim de ocorrência para a caracterização do crime de estelionato. 
O depósito do cheque fora das condições estabelecidas pelas partes, devido a relação jurídica verbal firmada, pode gerar o direito à responsabilização por danos materiais e morais para o emitente.

Então, e preciso que o portador do título de crédito esteja atento para as consequências que poderão advir, pois poderá sofrer condenação na esfera cível.

\section{REFERENCIAS}

ANDREATTA, V. R. O cheque pós-datado em vista das exigências da lei do cheque, 1ạed. São Paulo: Editora de Direito, 2004.

BRASIL, LEI № 9.492, DE 10 DE SETEMBRO DE 1997. Define competência, regulamenta os serviços concernentes ao protesto de títulos e outros documentos de dívida e dá outras providências. Diário Oficial da União, Brasília, DF, 11 set. 1997. Disponível em: <http://www.planalto.gov.br/ccivil_03/leis/I9492.htm> Acesso em: 14 ago 2014.

BRASIL, LEI No 7.357, DE 2 DE SETEMBRO DE 1985. Dispõe sobre o cheque e dá outras providências. Diário Oficial da União, Brasília, DF, 03 set. 1985. Disponível em: <http://www.planalto.gov.br/ccivil_03/leis/l7357.htm> Acesso em: 13 ago 2014.

BRASIL, LEI N ${ }^{\circ}$ 5.869, DE 11 DE JANEIRO DE 1973. Institui o Código de Processo Civil. Diário Oficial da União, Brasília, DF, 12 jan, 1973. Disponível em: < http://www.planalto.gov.br/ccivil_03/leis/15869.htm> Acesso em: 15 ago 2014.

COELHO, F. U. Curso de direito comercial. 110 ed. São Paulo: Atlas, 2013.

CAPEZ, F. Curso de Direito Penal, 12a ed. São Paulo: Saraiva, 2012.

FILHO, M. C. Cerveira Advogados Associados. Consequência dos Cheques sem Fundos. 2004. Disponível em: <http://www.cerveiraadvogados.com.br/site/conteudo_noticias.asp?s=3\&c=5\&id_noticia=194> Acesso em: 14 ago 2014.

GONÇALVES, V. E. R, Títulos de crédito e contratos mercantis. 7ạ ed. Vol. 22, São Paulo: Saraiva, 2011. Disponível em: <http://pt.slideshare.net/daianequesado7/sinopses-jurdicas-22-2011-ttulosde-crdito-e-contratos-mercantis-7-edio> Acesso em: 09 ago 2014.

NEGRÃO, R. Manual de direito comercial e de empresa, Títulos de crédito e contratos empresariais. 3a ed. São Paulo: Saraiva, 2012.

SIQUEIRA, D. Crédito e Cobrança. Cadastro de Emitentes de Cheques sem Fundos. 2005. Disponível em: <http://www.creditoecobranca.com/artigos/cheques/cadastro-de-emitentes-decheques-sem-fundos> Acesso em: 14 ago 2014. 